\title{
THE UBIQUITOUS BIOCHEMICAL LOGIC OF MURBURN CONCEPT
}

\author{
Kelath Murali Manoj* \\ Satyamjayatu: The Science and Ethics Foundation \\ Snehatheeram, Kulappully, Shoranur-2 (PO), Kerala, India
}

In peroxidative biotransformations, reactions occurring outside the enzyme's "active site" were seen to yield selective and specific outcomes. These observations had inspired me then to postulate that "such a non-active site and environment-dependent mechanism could play significant roles in life-sustenance processes, besides the well-established hierarchical molecular control mechanisms at genes' and proteins' levels". Through the decade that followed, further research on these strings culminated into the formation of murburn concept, a stochastic scheme of electron/moiety transfers and interactions among molecules, unbound ions and radicals present in reaction milieu. The new understanding explained key qualitative and quantitative aspects of heme/ flavin enzymology (substrate diversity, reaction stoichiometry, etc.) and electron transfer mechanism in these enzymes' in vitro setups. Further, murburn schemes were proposed to explain xenobiotic metabolism, cellular respiration, bio-thermogenesis and maverick physiological dose-responses. This article deals with a brief summation of the development of murburn concept, its current status and potential implications/applications in biology and medicine. Biomed Rev 2018; 29: 89-97

Keywords: murburn concept/scheme, ROS, diffusible reactive species, redox metabolism/disease, origin of life, evolution, metabolic logic

\section{THE FUNDAMENTAL COMPOSITION, NATURE AND FEATURES OF LIFE}

Parsing "chemically", matter exists in four fundamental states: atom, molecule, ion, and radical. Some chemical species may have multiple statures, i.g. hydrogen atom is also a radical, normal oxygen is both a molecule and a diradical, superoxide is an anion and a radical, etc. Since elemental atoms are rare in biology and radicals are relatively short-lived (oxygen being one of the rare exceptions!), all living matter is almost entirely made up of molecules and ions. Any typical cell would have more than millions to trillions of molecules and ions. Horowitz' molecular definition posits that an organism must have the ability to replicate, catalyze and mutate. Since most life processes are inherently "order-seeking", many of these three key life-sustaining biomolecular activities would need power. In that quest for power, of the fundamental physical

Received 20 December 2018, revised 25 December 2018, accepted 26 December 2018.

* Correspondence to: Dr Kelath Murali Manoj, Satyamjayatu: The Science \& Ethics Foundation, Kulappully, Shoranur-2 (PO), Kerala-679122, India E-mail: satyamjayatu@yahoo.com 
potencies (gravitational, electromagnetic, and strong/weak nuclear forces), living matter/beings are essentially driven by electromagnetic forces alone. Heat energy and chemical energy (sources like ATP) that drive biological phenomena are derived by the movement/transfer of electrons/moieties (charges) from one molecule to another. These sub/supramolecular transactions serve as a chemical powering system, thereby affording "a temporally operable (on/off), workable (thermodynamically viable in space-time) and controllable (tunable to increase or decrease, per demand) machine logic" to the chemico-physical entity called organism.

In the context of defining an organism, the central dogma of life is founded in the principle that genes give rise to proteins, which in turn, control and carry out most activities at the cellular or tissue level. Genes (aided by some proteins) direct and regulate the amounts and features of expressed proteins. That is, genes directly decide which protein should be expressed and indirectly govern how the protein behaves by virtue of some inherent information. Proteins, as the most versatile and selective molecular protagonists in the drama of life, directly determine what molecules are acted upon and what products would be generated in real space and time. [In a multi-cellular organism like man, other facets like neuronal and hormonal controls, temporal regulatory mechanisms based on "supra-molecular intelligence", are also present. These are not the immediate topics of concern here.] All these conventional gene-level and protein-level interactions, controls and outcomes are deterministic, aiding the order-seeking machinery of the cell/organism. Therefore replication, transcription and translation of genetic information by proteins are highfidelity processes. Also, most other reactions catalyzed by proteins and interactions featuring proteins are also selective (say, choosing C from multiple species like - A, B, C and D) and specific (reacting at one locus of the selected molecule $\mathrm{C}$, say at $\alpha$ site, when $\beta$ and $\gamma$ positions are also available). This predictability and reproducibility for protein-mediated processes result by the virtue of well-defined topographical and electrostatic complementary interactions with their destined substrates/counterparts, at a well-defined "active-site". That is, an affinity binding or interaction between the enzyme/protein and its substrate/ligand results in a molecular "recognition" process (the classical concepts of Fisher's lock \& key concept or Koshland's induced fit concept in enzymology, antigenantibody complementarity in immunology, etc.). In turn, such outcomes resulting from "sorptive" (adsorptive, absorptive and ion-exchange) interactions lead to a "transition state", which in turn, give a deterministic cascade of biological response(s) thereafter, like- signal transduction, molecular/ionic transport, catalysis/metabolism, homeostasis, etc.

Therefore, the perception has long prevailed that physiological electron transfers (intra-molecular or inter-molecular redox catalysis/metabolism mediated by proteins) occur through Marcus' outer sphere scheme (via a bonded or wired connectivity) alone. This belief existed because such a modality would enforce the deterministic mandate. Further, moiety transfers are believed to occur almost exclusively via transient enzymic intermediates' (transition state) direct active-site interaction with the substrate, via a ping-pong or concerted mechanism. Furthermore, in the interaction and reaction scheme of biomolecules (and ions), the presence or formation of free radicals were essentially seen as aberrant routes or outcomes. [There are exceptions, as exemplified by ribonucleotide reductase (RNR), cytochrome P450 (CYP), flavoenzyme $\mathrm{NAD}(\mathrm{P}) \mathrm{H}$ reductase (FNR), etc., which are perceived to go through a radical mechanism. However, the radical entity is believed to be localized on or within the enzyme, in the form of an iron-porphyrin radical, enzyme residue tyrosine radical, etc. The isolated case of a diffusible radical species like nitric oxide was also acknowledged to serve as a molecular messenger. However, the primary paradigm has been that diffusible radicals are/were yet seen as a manifestation of pathophysiology, and as agents of chaos.] The erstwhile mechanistic perceptions heavily dwelled on the utilization of 2e processes (transfer of electron pairs) to explain the interactive dynamics of molecules (and ions) that constitute cellular/ life machinery.

\section{THE HISTORY OF MURBURN CONCEPT}

While working on the versatile heme-thiolate enzyme chloroperoxidase (CPO) in Lowell Hager's lab at UIUC (19992000), I had questioned the standing "active-site" explanation for heme-enzyme mediated electron (abstraction of electron/ hydrogen atom from the final substrate) and moiety (insertion of a halogen atom on to the final substrate) transfer reactions. These works' publication took several more years only because peers in the field held on to the entrenched perception that "life mechanisms would not leave things to chance by allowing reactions to occur outside the active site". [This is quite similar to how some renowned scientists like Planck and Einstein had responded to the theories developed later in the field of quantum mechanics/electrodynamics, a field which they had themselves originally pioneered!] In 2006, I had deliberated 
upon the following insights:

(i) In a Biochimica Biophysica Acta paper (1) on chloroperoxidase-mediated chlorination reaction mechanism, it was shown that a redox enzyme could effectively work through a diffusible reactive intermediate to achieve selectivity and specificity. Further, in the same work, it was shown that the reaction components play multiple roles in the complex reaction system. In the conclusion, it was marked: "Routinely, genetic and enzymatic regulations of bioprocesses are stressed on. This work highlights upon the third aspect of determining the course of a biological reaction, i.e., the medium composition. It has been relatively overlooked because of the supposition that life could not have evolved and maintained its order if it were subjected to such chaotic courses of determination".

(ii) In an arXiv preprint article (2) on cytochrome P450s (CYPs) mediated microsomal xenobiotic metabolism (mXM), the above-mentioned ideas were applied and the abstract ended with the statement: "(The communication)..... ushers in a radically new concept that small amounts of diffusible reactive oxygen species (DROS) are pivotal in routine oxidative metabolism in the cell." And the manuscript concluded with the following lines- "Most importantly, this study-(a) reveals that sustained low concentrations of DROS is crucial to cellular oxidative metabolism of drugs involving hlmCYPs and (b) stresses on the relevance of self-regulating non-specific redox reactions in physiological milieu."

Since then, my (group's) works on a bevy of heme and flavin redox enzyme systems confirmed that these were not an isolated instances, and that in fact, several other heme/flavin enzymes (as exemplified by horseradish peroxidase, catalase,
CYPs and FNR) also recruited/used diffusible reactive oxygen species (DROS) for converting diverse "substrates" (1-22). This finding was besides the obvious and imminent fact that reactions mediated by DROS posed the "chaotic uncertainty" that they could meet their intended targets "outside the active site" for attaining their intended/accepted physiological function. In 2016, this new mechanistic understanding was formally called murburn concept (13-17). Since the studied reactions involved oxygen-centered entities as electron donors and acceptors, the term was coined to draw analogy (compare and contrast) with the spontaneous combustion reaction logic. (The common fire or burning in the open is a process which involves oxygen-centered radicals.) Also, the term implied that the metabolic reaction was a rather mured (closed) cum mild and $\underline{\underline{u}} \underline{\underline{r}}$ estricted burning. From the anagrammed expression, it can be understood that murburn concept is also a spontaneous/ downhill interactive scheme of $\underline{\mathbf{m}}$ olecules, $\underline{\mathbf{u}}$ bound ions and radicals. [Another comparison could also be made: quite like electrolytic or galvanic cells of chemistry have donors (source) and acceptors (sink) of electrons (and a conductive ionic bridge between such 'electrodes'), the cellular biomolecular redox scheme could have constitutive and stochastic functional analogs. The first analogy appeared to be simpler, and therefore, it struck a chord and stuck with me.] The different ingredients of this dynamic scheme are shown in Figure 1.

\section{A DEEPER AND SIMPLER UNDERSTANDING OF MURBURN CONCEPT}

Now, one could ask- how can a spontaneous downhill process like burning be selective/specific? A simple experiment

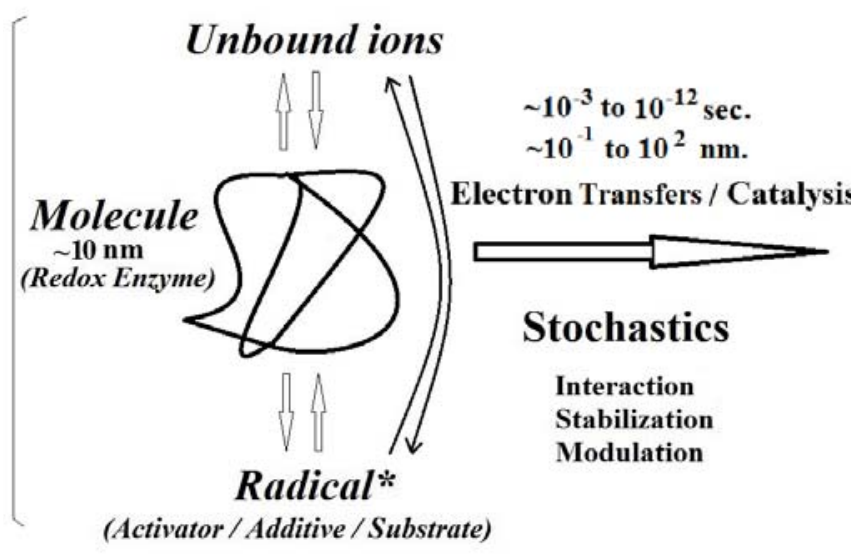

Figure 1: The essential components of murburn concept

\section{Constitutive controls}

Dynamic partitioning, Dielectrics, Concentrations, Protons, Spin, etc.

Fast discretized processes

Bimolecular, diffusion-limited reactions Selective/Specific outcomes

\section{Variable stoichiometry}

Case 1: $4 \mathrm{P}_{1}+1 \mathrm{P}_{3}+\ldots$.

Case 2: $2 \mathrm{P}_{1}+1 \mathrm{P}_{2}+3 \mathrm{P}_{3}+\ldots$. 
or consideration can prove the point- when a coin wrapped around by a few turns of a twine is suspended and subject to a flame (along the twine covering the coin), it takes quite a while for the twine to burn and release the coin. This is seen when the twine burns spontaneously at a much earlier time, when presented alone (in the absence of the metal coin). Similarly, when a cloth daubed in oil is set on fire, the fabric does not get charred as long as adequate oil is present. (This phenomenon is even more prominent if the cloth is first soaked in water, then in oil, and then the flame is presented for burning.) The first observation results because the provided heat energy is absorbed by the metal first and only when its temperature is raised above a critical point does the twine "get to absorb the heat". In the second instance, when provided a flame, the oil reacts much faster than the cloth, and therefore, the oil gets consumed first. In the examples cited above, depending on the chemico-physical attributes (heat capacity, flammability, flash point, etc.) the outcome can be selective. Quite analogously, small molecules could get preferentially reacted in the biological redox reaction milieu, sparing the larger macromolecules/ biopolymers and biological scaffolds/frameworks. The data in Figure 4 and Table 3 of an earlier work (1) are very fundamental to understanding this logic. In the figure, it can be seen how a reactive diffusible species like $\mathrm{HOCl}$ can kinetically differentiate between small molecules when the diffusible species is present in small amounts. However, when the diffusible species is present in high amounts, the small molecule substrates are not differentiated. The selectivity of this non-active site reac- tion is also modulated by environmental conditions like $\mathrm{pH}$ and ion concentrations, as seen in the aforementioned table. Therefore, such reaction logics would have formed the primary basis of selectivity and specificity in the primordial life soups.

In terms of kinetics, the murburn reaction logic could give very interesting substrate dependence curves. A classical Michaelis-Menten curve is a hyperbola, with variation of reaction rate being seen even up to millimolar concentration levels of the substrate (depending on the equilibrium constants like $\mathrm{K}_{\mathrm{d}}$ or $\mathrm{K}_{\mathrm{M}}$. The murzyme (an enzyme that works via murburn schemes) kinetics is rather unpredictable, with respect to the variations of the reaction components (1-22). That is- when the formation rate of the product of interest is noted with respect to increase in the substrate concentration, unusual profiles are obtained, as shown in Figure 2. In the right panel, practically a zeroth order kinetics can be seen even up to micromolar ranges (bold line aligned with $\mathrm{X}$-axis), as exemplified by the chlorination of several molecules by chloroperoxidase reaction (1) or utilization of NADPH by the CYP + reductase mixture (16). Such outcomes could be useful for cellular metabolism when a steady rate of product formation would be needed at diverse/low substrate levels. Only a diffusible radical species mediated reaction could give such an outcome. At times, murburn schemes afford sigmoid, bi- or multi- phasic profiles too $(5,15)$.

\section{THE FACILE EVOLUTIONARY LOGIC OF MURBURN SCHEMES}

As discussed earlier, life forms are made of molecules and ions,
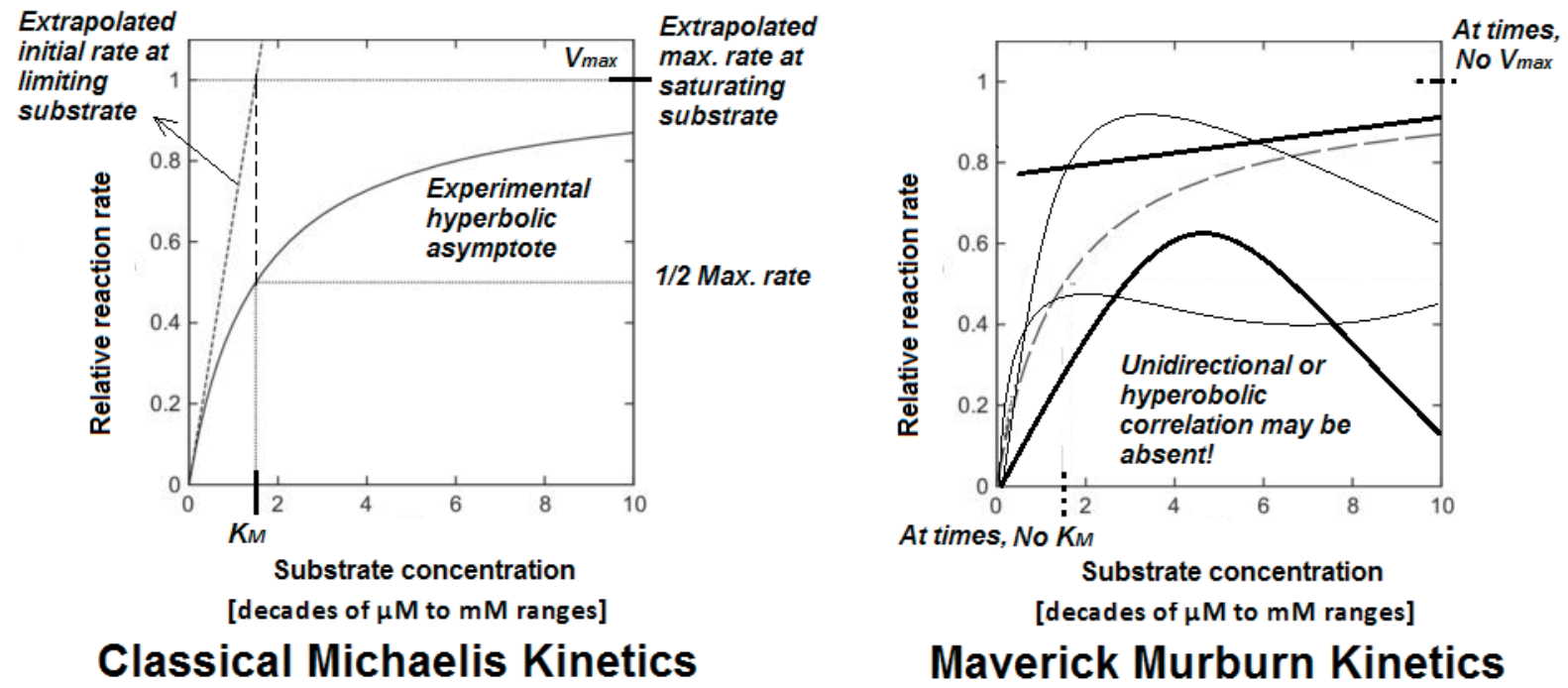

Figure 2: A comparison of experimental profiles of classical enzymes and murzyme reactions 
and therefore, it is only natural to expect a constitutive interactive equilibrium between molecules and ions. Consequentially, this equilibrium could be perturbed by/with the presence of a suitable radical. In turn, this seemingly chaotic trigger could serve as a process/reaction directing logic that could support/ affect life. Such a supposition is justified because if life forms evolved from chaos (as most scientists believe it to be!), it is only natural to deduce that chaos must also have a facet that supports life. Therefore, murburn concept (equilibriums between the molecules, ions and radicals that support/affect life and its prospects; Figure 1) would be one of the most primordial directive agents that resulted in the "nucleating" or "ordering" events that led to life. This is a simple reaction logic that affords selectivity and specificity without the mandating topographical or electrostatic complementarity between the reactants. So, the evolved murburn schemes of metabolism/ physiology could include a large set of events that incorporate both the classical (deterministic) sorption-based interactions and the uncertain (probabilistic) reactions/movements of diffusible species.

In this context, murburn concept affords profound insights on the evolutionary processes of life and physiological roles of oxygen and lipid-membranes within the cellular system. The reason why phospholipid membrane (rather than say, proteincapsids or glycan-walls) became the physical boundaries of cells becomes clearer now. Lipids, by virtue of their fluidic nature, allowed embedding of proteins along with the cofactors that enabled radical generation. Further, they are highly electron-rich and thus, acted as "radical-attractants", thereby providing a cushioning and sinking effect for the radicals generated, allowing the harnessing of the reaction potentials of radicals in their vicinities. Now, this simple lipid membrane facet also enabled the partitioning of reaction products, gave a framework of "demarcating the system from its surroundings" and thereby allowed the evolutionary scope for "sensing" and signal transduction cascades thereafter. Now, Figure 3 shows a comparison of the murburn scheme of mOxPhos (mitochondrial oxidative phosphorylation) with some powering systems that could be formed spontaneously or with minimal assembly. In contrast with the erstwhile "irreducibly complex" proton-centric schemes/logic shown in Figures 1 and 3 of a recent work (which feature highly deterministic and multimolecular sequential arrays that have little probabilistic scores in real physiological conditions) (20), the facile logic enabling spontaneous assembly of components in the murburn scheme of mOxPhos is evident. The analogies of simple cooking grill or nuclear reactor shows the operating principle. A source of heat/radicals/neutrons can set the process on and this is analogous to the function played by ROS in mitochondria. Other inbuilt controls are mere "add-ons" that enhance yields. While a hydroelectric power project or automobile (the powering logics of erstwhile explanatory schemes) cannot form on its own $(20,21)$, natural and spontaneous formation of hearths and nuclear reactor are well-known. Such analogies allow us to better appreciate the "evolvability" and "fine-tunability" of the reactor core's stochastic operative logic (DROS reacting randomly with various species in a "cauldron"), with a superior governing deterministic machinery (genes and proteins).
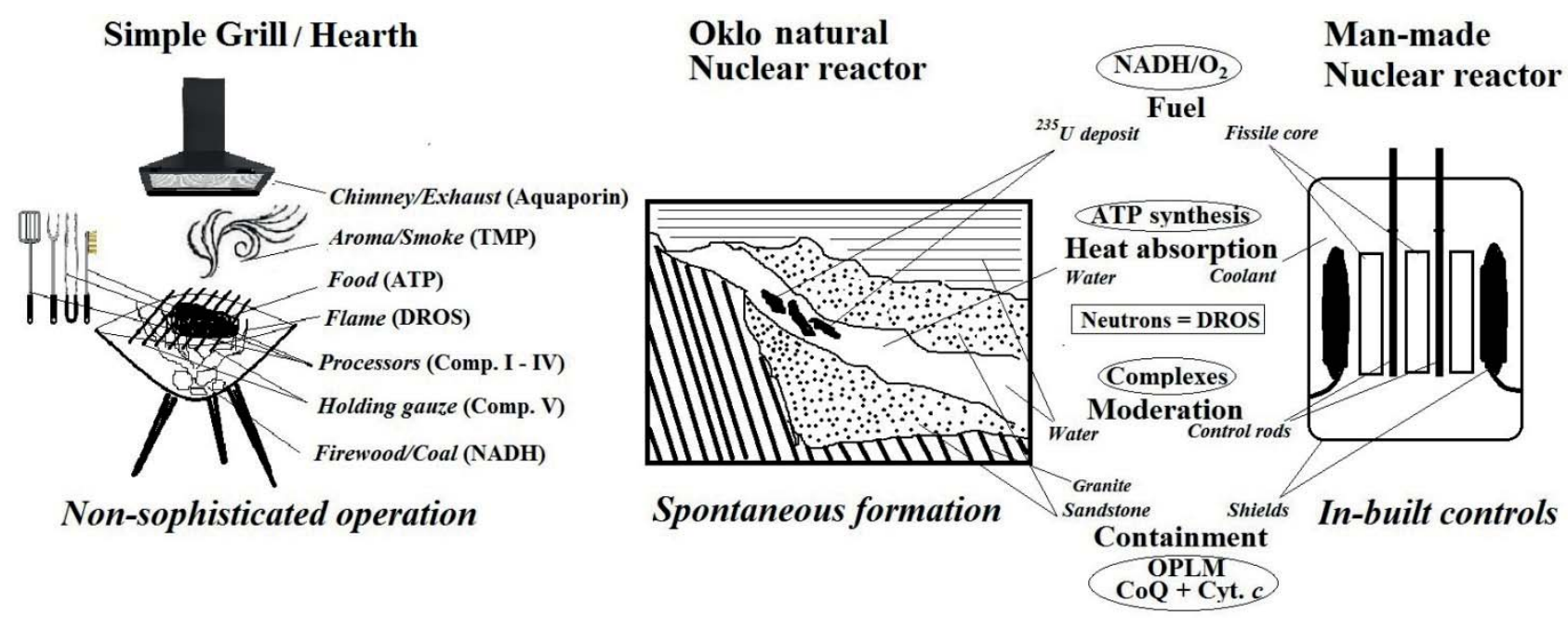

Figure 3: Analogies for murburn scheme of mOxPhos 


\section{APPLICATION OF MURBURN CONCEPT TO EXPLAIN BIOLOGICAL PHENOMENA}

Murburn concept posits that electron/moiety transfers (the quintessential chemical activities of life!) could also occur outside the "supposed" active sites of proteins/enzymes, with unbound ions and transiently formed radicals within milieu aiding the overall stochastic scheme $(14,15)$. Such a constitutive stochastic electron and moiety transfer process could also thereby many times aid cellular dictates. As this essay is being written at the end of 2018, murburn scheme has been proposed to explain key questions/aspects of cellular physiology and ecology-

(i) Ecology of naturally produced halogenics and recycling of lignocellulosics $(1,4,15)$ : How could enzymes insert halogen atoms at relatively non-reactive and inaccessible sites? How could the biological machinery break down the highly complexed and polymeric lignocellulosic structures?

(ii) Xenobiotic metabolism $(13,16,17)$ : How can the substrate diversity of certain CYPs be explained (Figure 4), when they are not (generally!) inducible by the same substrates? How can

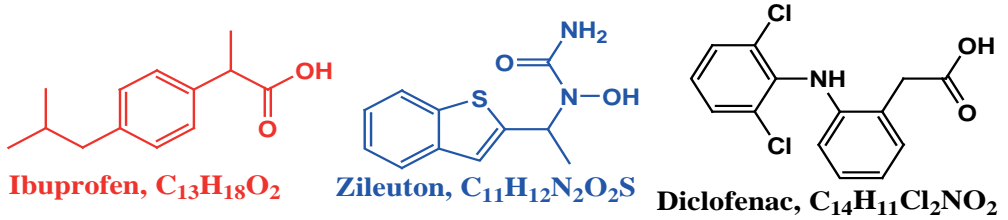

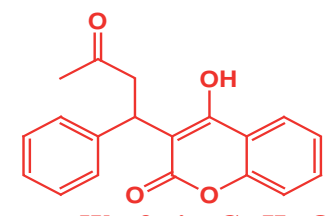<smiles>Cc1ccc(-c2cc(C(F)(F)F)nn2-c2ccc(S(N)(=O)=O)cc2)cc1</smiles><smiles></smiles>

Diclofenac, $\mathrm{C}_{14} \mathrm{H}_{11} \mathrm{Cl}_{2} \mathrm{NO}_{2}$ Amitriptyline, $\mathrm{C}_{20} \mathrm{H}_{23} \mathrm{~N}$

Tamoxifen, $\mathrm{C}_{26} \mathrm{H}_{29} \mathrm{NO}$

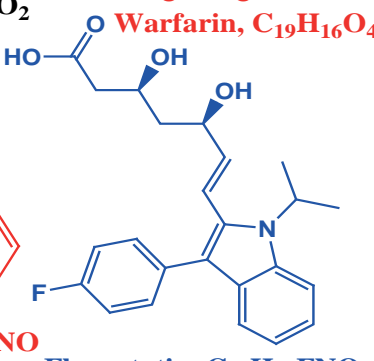

Celecoxib, $\mathrm{C}_{17} \mathrm{H}_{14} \mathrm{~F}_{3} \mathrm{~N}_{3} \mathrm{O}_{2} \mathrm{~S}$<smiles>COc1ccccc1OC1=C(OCCO)N=C(c2ncccn2)N(c2ccccc2S(N)(=O)=O)C1C(C)(C)C</smiles>

Fluvastatin, $\mathrm{C}_{24} \mathrm{H}_{26} \mathrm{FNO}_{4}$

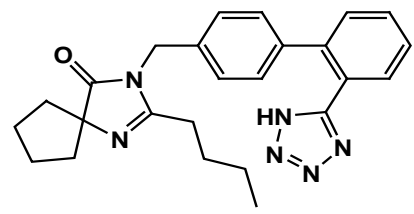

Irbesartan, $\mathrm{C}_{25} \mathrm{H}_{28} \mathrm{~N}_{6} \mathrm{O}$

Bosentan, $\mathrm{C}_{27} \mathrm{H}_{31} \mathrm{~N}_{5} \mathrm{O}_{6} \mathrm{~S}$
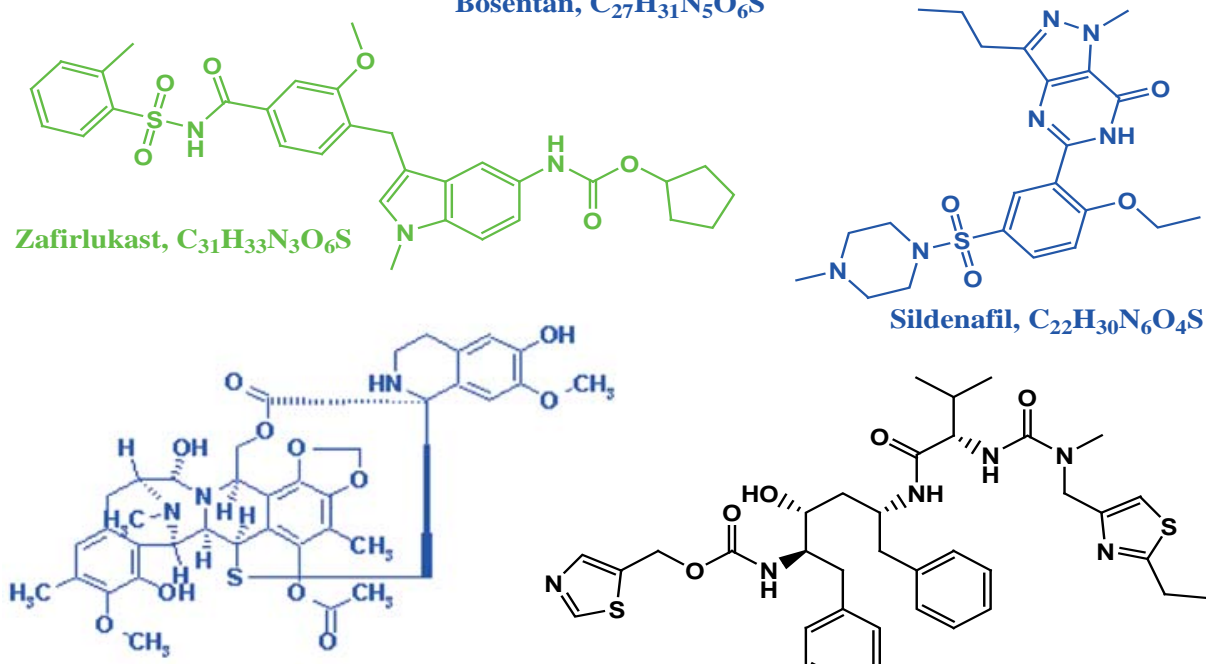

Sildenafil, $\mathrm{C}_{22} \mathrm{H}_{30} \mathrm{~N}_{6} \mathrm{O}_{4} \mathrm{~S}$

Trabectedin, $\mathrm{C}_{39} \mathrm{H}_{43} \mathrm{~N}_{3} \mathrm{O}_{11} \mathrm{~S}$<smiles>CCCc1nc(CN(C)C(=O)N[C@H](C(=O)N[C@@H](Cc2ccccc2)C[C@@H](Cc2ccccc2)[C@H](O)CNC(=O)OCc2cncs2)C(C)C)cs1</smiles>

Figure 4: Structural diversity of some CYP2C9 substrates (or competitive inhibitors) 
the sole FNR (or CYP-reductase) present at low concentrations donate electrons to copious amounts of diverse array of CYPs?

(iii) Maverick physiological dose-responses $(15,19)$ : How is hormesis explained, or how could a lower dose of a molecule generate a greater response than a higher dose? Why should certain molecules produce idiosyncratic responses (Figure 5) (individual-specific effects; it could give an outcome in one individual whereas in the other, it may be silent)?

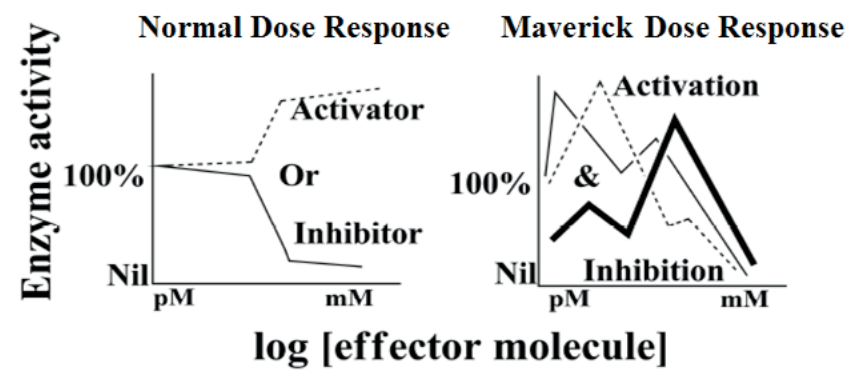

Figure 5: The phenomenon of maverick dose responses, including hormesis

(iv) Mitochondrial oxidative phosphorylation (mOxPhos, leading to the synthesis of ATP, the chemical energy currency that aids otherwise thermodynamically uphill processes) (18,20-21): Why does the incorporation of ADP \& Pi enhance the consumption of NADH and oxygen? Why do low amounts of cyanide inhibit mOxPhos and how do uncouplers affect the electron transport?

(v) bio-thermogenesis (production of heat, which facilitates biomolecular interactions and reactions) $(18,20-22)$ : What is the basic mechanism of heat generation and how do uncoupling proteins (in particular) generate heat?

The last two physiological routines (iii and iv) were otherwise explained under the purview of mechanisms like proton-centric chemiosmosis and trans-membrane potential generation cum harnessing/dissipation by membrane-bound enzymes/proteins. These were recently demonstrated to be physiologically non-viable options $(18,20)$.

It is purely a misplaced notion that proteins get easily denatured by ROS. While some proteins may be sensitive, others may be pretty rugged and turnover millions of molecules of ROS at high concentrations, before denaturing (23). Also, at times, a diffusible species mediated murburn assay (3) can be more reproducible than an active-site based assay for the same enzyme (24). Therefore, it is high time that we start to see beyond entrenched outlooks. It is now worth taking a stock of the salient aspects of three reaction systems (with increasing level of complexity, where murburn concept was applied to explain reaction outcomes) are captured in Table 1.

\section{PROJECTED IMPACT OF MURBURN CONCEPT IN BIOLOGY AND MEDICINE}

Therefore, murburn schemes would be relevant in "the stochastic interactions among biomolecules, ions and the small number of radicals (that could be generated transiently in situ)" that could aid the prospects of sustenance of life. The stochastic and uncertain nature of murburn mechanism does not necessarily connote disruption and total unpredictability. It merely implies a more complex set of conditionality for predicting reaction outcomes (as the outcome depends on a multitude of interconnected variables, as listed in Fig. 1) and perhaps a lower window of desired outcomes. This nascent field of biochemistry/ physiology is poised to enhance our understanding of important realms of metabolism and physiology, like- photosynthesis, cellular homeostasis, fixation of carbon and nitrogen and other redox metabolic schemes, threshold physiologies, signal transductions (conversion of physico-chemical stimuli like sight, smell, pressure, etc. into biological cues), development of action potential and neuronal relays, cybernetics, origin and evolution/ diversity of organisms, epigenesis, miscellaneous biosphere interactions, etc. In particular, a greater awareness of murburn concept is envisaged to afford us better means of understanding maverick physiological dose responses and redox diseases. In this context, the prevailing perceptions on DROS and lipids/ adipocytes interactive dynamics are reoriented (25). One day, we might be able to have diets and drugs tailored to individual redox metabolic requirements. Further, mainstreaming of sensible and statistically verifiable aspects of traditional Chinese and Indian medicine may be feasible along the lines of modern science. Wim Hof's mental control over thermic physiology and psycho-neuro-immunology (placebo effect, "unlearning allergy", etc.) would no longer be mystic secrets. I hope that researchers would soon warm up to the radical (pun intended!) opportunities that murburn concept poses and explore the bounties in store within this unchartered field.

\section{ACKNOWLEDGMENTS}

The idea of murburn concept would not have visualized without the magnanimity of (late) Lowell Hager (Emeritus Professor at UIUC), in whose lab I learned to think and work freely. This manuscript was powered by Satyamjayatu. 
Table 1: Comparison of murburn mechanism for chloroperoxidase/hemeperoxidases (CPO/HPO), mXM and mOxPhos systems.

\begin{tabular}{|c|c|c|c|c|c|}
\hline System & Cofactors & lons, pH \& ambiance & $\begin{array}{l}\text { e- Source; } \\
\text { [Substrate] }\end{array}$ & $\begin{array}{l}\text { Major reaction \& } \\
\text { product(s) }\end{array}$ & Relevance \\
\hline $\begin{array}{l}\frac{0}{0} \\
\frac{1}{8} \\
\frac{1}{1} \\
0 \\
\frac{2}{1}\end{array}$ & $\begin{array}{l}\text { Fe-Heme }\left(\mathrm{Mn}^{2+}\right)[1 \\
\text { protein and } 1 \text { cofactor } \\
\left(\mathrm{Mn}^{2+} \text { is optional for }\right. \\
\text { activity)] }\end{array}$ & $\begin{array}{l}\mathrm{H}^{+}, \mathrm{Cl}^{-} / \mathrm{Br}^{-} / \mathrm{I}^{-} \\
\text {acidic } \mathrm{pH} \\
\text { Purely aqueous system }\end{array}$ & $\begin{array}{l}\mathrm{H}_{2} \mathrm{O}_{2} \text { and organic } \\
\text { hydroperoxides; } \\
\text { [diverse types of } \\
\text { organics] }\end{array}$ & $\begin{array}{l}\text { Halogen atom } \\
\text { transfer, and/or } \\
\text { substrate oxidation. } \\
{\left[\mathrm{R}^{*+}, \mathrm{R}-\mathrm{R}, \mathrm{RCl}\right.} \\
\mathrm{RCl}-\mathrm{R}^{\prime} \mathrm{OH}, \mathrm{R}=\mathrm{O} \text {, etc.] }\end{array}$ & $\begin{array}{l}\text { Explains halogenated } \\
\text { organics' formation and } \\
\text { lignocellulosics' cycling in } \\
\text { the environment }\end{array}$ \\
\hline \multicolumn{6}{|c|}{ 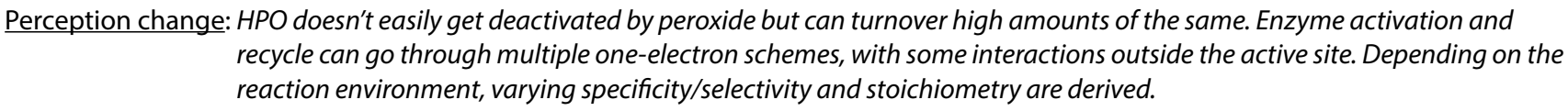 } \\
\hline 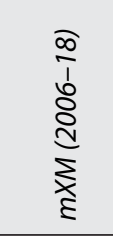 & $\begin{array}{l}\left.\text { Fe-Heme (P450, Cyt. } b_{5}\right) \\
\text { Flavins (reductase) } \\
\text { (Fe-S centers in auxiliary } \\
\text { systems; Cyt. } b_{5} \text { optional) } \\
\text { [3 proteins and } 4 \\
\text { cofactors] }\end{array}$ & $\begin{array}{l}\mathrm{H}^{+}, \mathrm{OH}^{-} \text {; neutral } \\
\mathrm{pH} \text {; Interfacial } \\
\text { system, uncoupling } \\
\text { high without lipid } \\
\text { embedding }\end{array}$ & $\begin{array}{l}\mathrm{NADPH}+\mathrm{O}_{2} \\
\text { [primarily } \\
\text { hydrophobic] }\end{array}$ & $\begin{array}{l}\text { Oxygen atom } \\
\text { insertion or hydroxyl } \\
\text { moiety transfer. } \\
{[R O H, R=O \text {, etc. }]}\end{array}$ & $\begin{array}{l}\text { Explains the metabolism } \\
\text { (utilization or expulsion) of } \\
\text { "unnatural" or "evolutionarily } \\
\text { alien" molecules in/from the } \\
\text { organism }\end{array}$ \\
\hline \multicolumn{6}{|c|}{$\begin{array}{l}\text { Perception change: Primary step in oxygen activation is carried out by flavin (not heme!). Electron transfer between CYP \& FNR occurs via } \\
\text { superoxide, not via protein-protein complexation. Xenobiotic need not interact with CYP at the distal heme pocket. A } \\
\text { thermodynamic pull (constitutive mechanism) operates to regulate the consumption of redox equivalents. }\end{array}$} \\
\hline 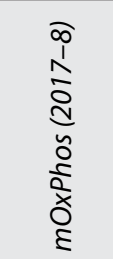 & $\begin{array}{l}\text { Complexes with Fe- } \\
\text { hemes, Flavins and Fe-S } \\
\text { centers, quinones, etc. } \\
\text { [Several tens of proteins } \\
\text { and cofactors] }\end{array}$ & $\begin{array}{l}\mathrm{H}^{+}, \mathrm{OH}^{-}, \mathrm{HPO}_{4}^{2-},\left(\mathrm{Mg}^{2+}\right) ; \\
\text { values around neutral } \\
\mathrm{pH} ; \text { closed vesicles } \\
\text { with membrane-laden } \\
\text { catalysts }\end{array}$ & $\begin{array}{l}\mathrm{NADH}+\mathrm{O}_{2} ; \\
\text { amphipathic } \\
\text { AdP-OH (ADP) }\end{array}$ & $\begin{array}{l}\text { Phosphate group } \\
\text { transfer. } \\
\text { AdP-OP (ATP), } \mathrm{H}_{2} \mathrm{O}_{2}\end{array}$ & $\begin{array}{l}\text { Explains the fundamental } \\
\text { powering routing of cells, } \\
\text { whereby ATP and heat are } \\
\text { generated by the oxidation } \\
\text { of metabolic fuel. }\end{array}$ \\
\hline & $\begin{array}{l}\qquad(\boldsymbol{x}) \mathbf{A d P}-\mathbf{O H} \\
\text { hange: The mitochondri }\end{array}$ & $+(x) \mathrm{P}-\mathrm{OH}+\mathrm{NADH}+\mathrm{O}_{2}$ & $\rightarrow(\boldsymbol{x}) \mathbf{A d P}-\mathbf{O P}+\mathbf{N}$ & $D^{+}+(x-1) \mathrm{H}_{2} \mathrm{O}+\mathrm{H}_{2} \mathrm{O}_{2}$ & $\begin{array}{l}\text { capitalizes on the proton- } \\
\text { neration/modulation and }\end{array}$ \\
\hline
\end{tabular}

\section{REFERENCES}

1. Manoj KM. Chlorinations catalyzed by chloroperoxidase occur via diffusible intermediate (s) and the reaction components play multiple roles in the overall process. Biochim Biophys Acta 2006;1764:1325-1339. doi:10.1016/j. bbapap.2006.05.012.

2. Manoj KM. The di-flavoenzyme reductase directly activates oxygen for the metabolism of diverse drug molecules by liver microsomal Cytochrome P450s. arXiv preprint q-bio/0610036 2006.

3. Manoj KM, Hager LP. A colorimetric method for detection and quantification of chlorinating activity of hemeperoxidases. Anal Biochem 2006;348:84-86.

4. Manoj KM, Hager LP. Chloroperoxidase, a Janus Enzyme. Biochemistry 2008;47:2997-3003. doi:10.1021/ bi7022656.

5. Manoj KM, Baburaj A, Ephraim B, Pappachan F, Maviliparambathu PP, Vijayan UK, et al. Explaining the atypical reaction profiles of heme enzymes with a novel mechanistic hypothesis and kinetic treatment. PLoS One 2010;5:e10601. doi:10.1371/journal. pone.0010601. 
6. Manoj KM, Gade SK, Mathew L. Cytochrome P450 reductase: a harbinger of diffusible reduced oxygen species. PLoS One 2010; 5: e13272. doi:10.1371/journal. pone.0013272.

7. Andrew D, Hager L, Manoj KM. The intriguing enhancement of chloroperoxidase mediated one-electron oxidations by azide, a known active-site ligand. Biochem Biophys Res Commun 2011;414:646-649. doi:10.1016/j. bbrc.2011.10.128.

8. Parashar A, Manoj KM. Traces of certain drug molecules can enhance heme-enzyme catalytic outcomes. Biochem Biophys Res Commun 2012;417:1041-1045. doi:10.1016/j.bbrc.2011.12.090.

9. Gideon DA, Kumari R, Lynn AM, Manoj KM. What is the Functional Role of N-terminal Transmembrane Helices in the Metabolism Mediated by Liver Microsomal Cytochrome P450 and its Reductase? Cell Biochem Biophys 2012; 63: 35-45. doi:10.1007/s12013-012-9339-0.

10. Gade SK, Bhattacharya S, Manoj KM. Redox active molecules cytochrome $c$ and vitamin $C$ enhance heme-enzyme peroxidations by serving as non-specific agents for redox relay. Biochem Biophys Res Commun 2012;419:211-214. doi:10.1016/j.bbrc.2012.01.149.

11. Parashar A, Gade SK, Potnuru M, Madhavan N, Manoj KM. The curious case of benzbromarone: insight into super-inhibition of cytochrome P450. PLoS One 2014; 9: e89967. doi:10.1371/journal.pone.0089967.

12. Parashar A, Venkatachalam A, Gideon DA, Manoj KM. Cyanide does more to inhibit heme enzymes, than merely serving as an active-site ligand. Biochem Biophys Res Commun 2014;455:190-193. doi:10.1016/j. bbrc.2014.10.137.

13. Venkatachalam A, Parashar A, Manoj KM. Functioning of drug-metabolizing microsomal cytochrome P450s- 1. In silico probing of proteins suggest that the distal heme ,active site" pocket plays a relatively, passive role' in some enzyme-substrate interactions. In Silico Pharmacol 2016;4:1. doi:10.1186/s40203-016-0016-7.

14. Manoj KM, Gade SK, Venkatachalam A, Gideon DA. Electron transfer amongst flavo-and hemo-proteins: diffusible species effect the relay processes, not protein-protein binding. RSCAdv 2016;6:24121-24129. doi: 10.1039/ C5RA26122H.

15. Manoj KM, Parashar A, Avanthika V, Goyal S, Moharana
S, Singh PG, et al. Atypical profiles and modulations of heme-enzymes catalyzed outcomes by low amounts of diverse additives suggest diffusible radicals' obligatory involvement in such redox reactions. Biochimie 2016;125:91-111. doi:10.1016/j.biochi.2016.03.003.

16. Manoj KM, Parashar A, Gade SK, Venkatachalam A. Functioning of microsomal cytochrome P450s: Murburn concept explains the metabolism of xenobiotics in hepatocytes. Front Pharmacol 2016;7. doi: 10.3389/ fphar.2016.00161.

17. Manoj KM, Venkatachalam A, Parashar A. Metabolism of xenobiotics by cytochrome P450: novel insights into the thermodynamics, kinetics and roles of redox proteins and diffusible reactive species. Drug Metab Rev 2016;48:4142. doi:10.1080/03602532.2016.1191848.

18. Manoj KM. Debunking chemiosmosis and proposing murburn concept as the explanation for cellular respiration. Biomed Rev 2017; 28: 35-52. doi:10.14748/bmr.v28.4450

19. Parashar A, Gideon DA, Manoj KM. Murburn concept: A molecular explanation for hormetic and idiosyncratic dose responses. Dose Response. 2018; 16:1559325818774421. doi:10.1177/1559325818774421.

20. Manoj KM. Aerobic respiration: Criticism of the proton-centric explanation involving rotary ATP synthesis, chemiosmosis principle, proton pumps and electron transport chain. Biochem Insights 2018. doi 10.1177/1178626418818442.

21. Manoj KM, Parashar A, Jacob VD, Ramasamy S. Aerobic respiration: Proof of concept for the murburn perspective. J Biomol Str Dynam 2018. doi: 10.1080/07391102.2018.1552896.

22. Manoj KM. Murburn scheme for thermogenesis mediated by uncoupling protein. arXiv:1812.06089 [q-bio.SC] 2018. Biomed Rev 2018; 29: xx-xx.

23. Manoj KM, Hager LP. Utilization of peroxide and its relevance in oxygen insertion reactions catalyzed by chloroperoxidase. Biochim Biophys Acta 2001;1547:408-417. doi: 10.1016/S0167-4838(01)00210-2.

24. Manoj KM, Yi X, Rai GP \& Hager LP. A kinetic epoxidation assay for chloroperoxidase. Biochem Biophys Res Commun 1999;266:301-303. doi:10.1006/bbrc.1999.1810.

25 Jacob VD, Manoj KM. Are adipocytes and ROS villains, or are they protagonists in the drama of life? The murburn perspective. Adipobiology 2018; 10: xx-xx. 